huwever, are sufficient to show that the earlier spectral types are associated with the shorter periods. Among the twenty stars in question, the earliest type at maximum is that shown by RS Boötis, which is B8, passing to $F_{0}$ at minimum. The most advanced type at maximum is shown by $\mathrm{U}$ Vulpeculæ, which is F7, and passes to $\mathrm{G}_{5}$ at minimum. The periods of these two stars are respectively 0.377 day and 7.990 days. No Cepheid variable hitherto observed has failed to show variability of the spectrum, and it is probable that all the variables of this class are subject to similar periodic disturbances of the radiating surfaces. Dr. Shapley has previously stated his reasons for rejecting attempted explanations which are based on a supposed binary character of the Cepheid variables, and for regarding the variations as arising from pulsations in a single body.

Daylight Photography of Stars.--Some interesting experiments on the photography of stars in daylight have been made by Messrs. A. F. and F. A. Lindemann (Monthly Notices, R.A.S., vol. Ixxvii., p. 140). Following the indications of a theoretical investigation as to the greatest contrast between sky and star, the photographs were taken on panchromatic plates through red filters, which only transmitted light of wave-length greater than 6700 A. With the 6-in. refractor employed, it was found possible in this way to photograph stars down to third magnitude, at distances of $20^{\circ}$ or $30^{\circ}$ from the sun. It is thought that in a fine climate it might be possible to photograph stars even fainter than first or second magnitude when quite close to the sun. The object of the experiments was to ascertain the practicability of testing, without an eclipse, the slight deviation of a ray of light by the sun's attraction which is indicated by Einstein's theory.

Report of the Cape Observatory.-The report of H.M. Astronomer at the Cape of Good Hope for the year $19{ }^{5}$, which has recently been received, indicates that the work of the observatory was carried on in all departments with but little interference from war conditions. Besides the usual meridian observations with the reversible transit, II8 parallax stars were under observation with the 8-in. transit circle, with an average of five comparison stars for each. Photographs of the sun, supplementing those obtained at Greenwich, were taken on no fewer than $3{ }^{1} 5$ days. The arrangements made for the daily, transmission of a wireless time-signal for the use of shipping in South African waters proved very satisfactory.

\section{THE THEORY OF ISOSTASY AS APPLIED \\ TO THE QUATERNARY OSCILLATIONS OF SEA-LEVEL.}

$\mathrm{I}^{*}$ view of the publication by the Geological Survey of Canada of a very important paper ${ }^{1}$ dealing with the application of the theory of isostasy to the Quaternary oscillations of sea-level, it seems desirable to give here a short résumé of the theory, and to point out to what extent the newly recorded observations tend to place it on a firmer basis.

It will be recalled that this theory ascribes the raised and tilted shore-lines, which are found around the centres of glacial dispersal, to the sinking in of the earth's crust beneath the pressure of the ice-sheets and its subsequent recovery when the ice has melted away. The depression and recovery were greatest at the centres of dispersal, where the ice was thickest, with the consequence that the shore-lines are highest near these centres and descend gradually towards the mar-

1 W. A. Johnston: "Late Pleistocene Occillations of Sea-level in the Ottawa Valley." Geological Survey of Canada. Museum Bulletin, No. 24, September 15, 1916.

$$
\text { NO. } 2469 \text {, VOL. } 98]
$$

gins of the glaciated districts. Before they actually reach these margins they pass beneath the present sea-level, so that there are no Late Glacial raised beaches in the peripheral part of the glaciated districts. The shore-lines which were formed during the retreat of the ice from these areas are all beneath the present sea-level.

Now the occurrence of this state of things in connection with all the Quaternary ice-sheets is very strong evidence of a general lowering of the oceanlevel during the glaciation. Moreover, calculations based on the quantities of water which must have been bound up in these ice-sheets, and so removed from the ocean, seem to indicate that this cause is quite adequate to produce the observed effects.

We have, therefore, in seeking for an explanation of the Late Glacial changes in the relative level of land and sea, two factors to deal with. The first is the local isostatic recovery of the earth's crust, the second is the general raising of level of the ocean due to the melting of the ice-sheets. According as the first or second of these factors predominated, there occurred either emergence or submergence in the isostatically affected areas.

This appears to be the explanation of the curious fact established by W. C. Brøgger in the Christiania region, that the first change of level after the retreat of the ice was one of submergence, which, at a somewhat later stage of retreat, gave place to emergence. That this is the course of events to be expected from the interplay of the two factors mentioned is apparent from the following considerations.

(I) At the period of deposition of the earlier Late Glacial marine deposits from which Brøgger drew his conclusions, about one-third to one-half of the total retreat of the ice margin had been accomplished; and it is roughly at this stage of retreat, when the climate had already considerably ameliorated, and there was at the same time a large body of ice still in existence, that the most rapid return of water to the ocean is to be expected.

(2) Brøgger has clearly established that the isostatic recovery progressed with a wave-like motion from south to north along the Cattegat, following up the retreating ice-margin. This seems to indicate that the recovery took some time to get under way, and did not attain its maximum rate until the neighbourhood was altogether clear of ice.

At this particular period of retreat, therefore, it would be natural to expect that the rise of the ocean level might be, for a time, faster than the isostatic recovery, and submergence would result. Later, when the isostatic recovery had gathered pace, and the amount of water returning to the ocean from the waning ice-sheets had become gradually less, we might expect the isostatic recovery to get the upper hand and give us progressive emergence.

Now the best test of the validity of this theory is its applicability to the isostatically affected areas of the British Isles and North America. Unfortunately in the British Isles the highest Late Glacial shore-line is only $100 \mathrm{ft}$. above the present sea-level, and within this small vertical range evidence of the kind utilised by Brøgger is not to be expected. In North America, until the appearance of the paper above mentioned, no investigation such as would bring to light a relation of this nature appears to have been placed on record. Johnston now brings forward evidence, of a nature similar to that adduced by Brøgger, to show that the Late Glacial changes of sea-level in the Ottawa valley were precisely the same as those established for the Christiania region, namely, that the sea first rose on the land as the glaciers retreated, and that it was not until a later date that emergence supervened. Moreover, he makes a further point of great importance 
in establishing the isostatic theory on a firm basis. This point, for which there is no direct evidence in the Norwegian case, is to the effect that the tilting of the Great Lakes region was in progress before and during the rise of the sea in the Ottawa valley, for, presumably from a comparison of contemporaneous ice-margins, it is concluded that "the Ottawa valley must have been, in part at least, occupied by the icesheet during the existence of Lakes Iroquois and Algonquin, and at least a small amount of uplift affected the region at the foot of Lake Ontario during the life of Lake Iroquois. Uplift also affected the northern portion of the Great Lakes region, and probably included the upper portion of the Ottawa valley near Mattawa during the existence of Lake Algonquin, and while the ice-sheet still occupied the upper portion of the Ottawa valley." Further, it is not a case of alternating elevation and depression, "for the result of investigations by numerous geologists of the raised beaches of the Great Lakes region has shown that differential uplift took place almost continuously as the ice withdrew."

We have thus direct proof that a district which was rising relatively to those around it was nevertheless undergoing submergence beneath the level of the sea. This remarkable phenomenon can have but one explanation, namely, that the isostatic recovery and the general rise of the ocean-level were in progress simultaneously, and that for a time the latter was the more rapid. Norway up to the present has only supplied a measure of the difference of these two motions. To presume their concerted action was a leap in the dark. Canada has now produced unexpected evidence of their individual existence.

There is now but one thing wanting to make the analogy between the isostatic phenomena of America and Europe perfect in every detail, and that is the discovery of a shore-line corresponding to the "Early Neolithic" or "Littorina-Tapes" raised beaches of Great Britain and Scandinavia. This should represent in the south a distinct resubmergence, and in the north a pronounced check or slowing down in the general emergence. W. B. WRIGHT.

\section{PLANT DISEASES.}

THE rôle played by insects in the spread of plant diseases is well brought out in the case of the collar-rot of rubber trees (Hevea brasiliensis), recently investigated by Sharples (Bull. 25, Dept. of Agriculture, Federated Malay States, 1916). The disease is caused by the fungus Ustulina zonata, as Brooks (Bull. 22, F.M.S.) has already shown. Sharples finds that at the time when the trees in a young rubber plantation are thinned out, at the age of about six or seven years, attacks by boring beetles (Xyleborus parvulus) become very common. He shows that these insects easily enter trees the bark of which has been injured by the falling of one tree against another. Attacks by the above-mentioned fungus usually quickly follow the beetles which enter rubber trees, the tracks of the insects being convenient ports of entry for the wound-parasite, $U$. zonata. At the time of thinning a large amount of suitable food material for the fungus is available in the form of soft rubber wood. Owing to the increased development of the fungus under these conditions in conjunction with the greater prevalence of borer attacks during the same period, it follows that the thinning-out stage is the most dangerous one in the life of a plantation as regards the attacks of this fungus on rubber trees.

To No. ro of the twelfth volume of the South African Journal of Science, published in May of the present year, Dr. Ethel M. Do:dge contributes a paper on the occurrence in South Africa of Bacterium campestre, the organism which causes the black-rot disease of the cabbage and other cruciferous crops. This organism had formerly been recorded only from Europe, America, and New Zealand, but Miss Doidge's investigations showed that the disease caused by it was quite common in the neighbourhood of Pretoria. The most interesting point about the communication is that it seems clear that the organism in the case under consideration was introduced into South Africa on cabbage seed which came from England. From cabbage seeds imported by the nuseryman to whose premises the diseased plants first observed by Miss Doidge were traced, the organism was isolated and its virulence proved by the successful artificial inoculation of two healthy cabbage plants. It was suggested nearly twenty years ago by Stewart in America that this disease was probably disseminated by seedsmen, but actual proof was then wanting. Soon after this the organism was isolated by Harding from the surface of cabbage seed produced by diseased plants in Long Island; and now Miss Doidge has shown that by such means the disease may be carried from one continent to another. Soaking suspected seed for fifteen minutes in $I: 240$ formalin or in I : 1000 mercuric chloride is recommended as a suitable method of treatment.

The cause of the serious disease of the potato known as the "Blattrollkrankheit" (leaf-roll disease) has been a matter of considerable controversy. The earlier investigators regarded the disease as being due to the choking of the wood-vessels of the plant with fungus mycelium. Recent researches, however, have shown that plants suffering from the choking of their vessels (hadromycosis) are not to be confounded with those affected with the true leaf-roll disease in which mycelium is absent. Quanjer, in.1913, found necrosis of the phloem to be a characteristic symptom of true leafroll in Holland; and in his most recent publication (Med. van d. Rijks Hoogere Land-, Tuin- en Boschbouwschool, Deel x., Wageningen, 1916) this author claims to have proved that the disease is due to a transmissible virus. Since attempts made to infect healthy potato plants by means of injections of the sap of diseased plants did not succeed, it might be thought that the claim is not justified. However, successful transmission of the disease was brought about in grafting experiments both with stalks and with tubers. Further evidence in favour of the virus is claimed to be afforded by the failure to isolate any parasitic organisms from affected plants, by the method of spread of the disease, by the uncertain results of selection as a means of raising healthy stocks of plants, and by the infection of healthy plants when transferred to diseased surroundings either through the agency of the soil (in which it is believed that the virus is often present) or from neighbouring diseased plants. It would seem that further research is necessary in order to supply absolutely convincing proof of the virus theory of the origin of this disease. Should it turn out to be a correct one, this disease, which has already made its appearance in some parts of Great Britain, will probably become more or less widespread in a few years unless some measures are taken to check it. The publication referred to is published in both the Dutch and the English languages.

COAL AND ITS ECONOMIC UTILISATION. THE economic importance of coal we perhaps realise. It is the only raw material we produce in great quantity; the value of our total mineral output in 1913 was above $160,000,000 l$. ; of this the value of the coal at the mine was above 145,500 ,oool.

Our output of coal and our home consumption in

1 Abridged from the Howard Lectures delivered before the Royal Society of Arts on November 27, December 4, and December 11, 1916, by Prof $J$ S. S. Hirame. NO. 2469 , VOL. 987 